\title{
POWER STABILITY MONITORING BASED ON VOLTAGE INSTABILITY PREDICTION APPROACH THROUGH WIDE AREA SYSTEM
}

\author{
${ }^{1}$ Goh, H.H., ${ }^{1}$ Q.S. Chua, ${ }^{1}$ S.W. Lee, ${ }^{1}$ B.C. Kok, ${ }^{2}$ K.C. Goh and ${ }^{3}$ K.T.K. Teo \\ ${ }^{1}$ Department of Electrical Power Engineering, Faculty of Electrical and Electronic Engineering, \\ ${ }^{2}$ Department of Construction Management, Faculty of Technology Management and Business, \\ Universiti Tun Hussein Onn Malaysia, 86400 Parit Raja, BatuPahat, Johor, Malaysia \\ ${ }^{3}$ Modelling, Simulation and Computing Laboratory, Level 3, Block C, \\ School of Engineering and Information Technology, Jalan UMS, \\ Universiti Malaysia Sabah, 88400 Kota Kinabalu, Sabah, Malaysia
}

Received 2014-01-23; Revised 2014-01-24; Accepted 2014-02-10

\begin{abstract}
Nowadays, power systems are being forced to operate closer to its security limit due to current economic growth and the difficulties to upgrade the existing grid infrastructure. With the sudden increment of power demand, voltage instability problem has become a main concern to the power system operator because voltage instability has led or crucially contributed to some major blackouts throughout the world. Hence, methods for early warning and early prevention are required to prevent the power system from a collapse and led to blackout. Real-time voltage instability predictor method is applied on one of the load areas in Tenaga Nasional Berhad (TNB) network in this study. Voltage instability predictor calculation is performed according to the real-time measurement provided by Phasor Measurement Units (PMUs). The voltage instability predictor calculates the power margin and makes comparison to the pre-set margin threshold. Last but not least, the stability condition of the system is based on the comparison between the margin and the pre-set threshold. The main perception is to ensure the margin index always stay positive and suitable early prevention should be implemented when the index is close to zero.
\end{abstract}

Keywords: Discrete Kalman Filter (DKF), Phasor Measurement Units (PMUs), Radial Equivalent Independent (REI) Network, State Estimation, Thevenin Equivalent, Voltage Instability Predictor (VIP), Wide Area Measurement System (WAMS)

\section{INTRODUCTION}

Voltage instability is a non-linear phenomenon and closely related to the perception of maximum deliverable power limit of a transmission network (Taylor, 1994). Due to voltage instability occurs from the time duration of $10 \mathrm{sec}$ up to few minutes' range of time periods (Kundur, 1994), voltage stability of a stressed power system should be monitored in real-time so that suitable control measures can be taken in a timely manner. Otherwise, voltage instability may lead to voltage collapse in the system or subsystem. Voltage collapse is the evolution where the voltage falls to a low, unacceptable value and caused avalanched accompanying with voltage instability (Hill, 1993; Taylor, 1993; Kundur et al., 2004).

Therefore, there are several well-known countermeasures were introduced in order to prevent voltage collapse, but the main constraint was lacked of information related to the current system state (Ajjarapu and Meliopoulos, 2008). Hence, this problem will lead the system to incorrect or delayed correction actions and thus will give a chance of instability occurrence. Nowadays, with the advancement of Phasor Corresponding Author: Goh, H.H., Department of Electrical Power Engineering, Faculty of Electrical and Electronic Engineering, Universiti Tun Hussein Onn Malaysia, 86400 Parit Raja, BatuPahat, Johor, Malaysia 
Measurement Units (PMUs) technology, it provides fast and efficient ways to improve the current power system state estimation (Hurtgen and Maun, 2008). PMUs technology has been widely developed and researched since the past 32 years and PMUs have been deployed throughout different parts of the world such as North America, Europe, China and India (Chakrabarti et al., 2009).

With continually increasing load demand $(3.5 \%$ per annum for the next 10 years) and increasing fuel costs (natural gas as experienced in the last two quarters of financial year 2011) (TNB, 2011), there is an urgent need to improve operational efficiencies utilization of transmission and distribution assets and reduction of losses. Therefore, Tenaga Nasional Transmission (TNBT) and Tenaga Nasional Berhad Research (TNB-R) have been joint cooperate on a 5-year research and development project on Wide-Area Intelligent System (WAIS) to enhance security and reliability of the power system network and at the same time to maximize the utilization of its assets. The introduction of Real-time Voltage Stability Margin (RTVSM) is one of the latest systems monitoring modules of WAIS to provide system operators information on proximity of the system to voltage collapse.

There are few factual of conducting this research on methods for early warning and prevention of voltage instability. Using PMUs technology performs the improvement of the current power system's state estimation by using PMUs technology. The implementation of an early-warning method on voltage instability for prevention purpose is going to be conducted. The investigations towards the availabilities of countermeasure are for prevention purpose. Last but not least is to improve the dispatching quality of the system towards stability borders.

The extent of the research was restricted to several limitations. The simulation results are mainly referred to the Tenaga Nasional Berhad $132 \mathrm{kV}$ load area for 2-Bus system and 10-Bus system. Since the communication channels at some Tenaga Nasional Berhad (TNB) substations are not fully configured, RTVSM based on actual data streams are still unattainable at the moment. Hence, the results shown are based on input from simulations. In fact, the actual data from the applied PMUs in the system will never find any voltage collapse occurrences. The main reason is because the existing transmission lines are equipped with the protection and countermeasure systems to make an early prevention from the collapse. Subsequently, voltage collapse such as fault occurrence or tripping on the bus will be created with the Real-Time Digital Simulator (RTDS) in order to obtain the required PMUs data. Moreover, the RTDS simulated data obtained from the TNB-R are in the form of voltage, current, active power and reactive power per phase values.

For the time being, TNB-R is implementing the current PMUs technology that can measure 50 samples per second, which is equal to 1 sample per $0.02 \mathrm{sec}$ (Abdullah and Yusuf, 2008). The experimental performance of simulation was conducted at TNB-R with the $132 \mathrm{kV}$ load area under investigation on 2Buses System and 10-Buses System.

In this study, the implementation of voltage instability predictor calculation according to the realtime measurement provided by PMUs in TNB $132 \mathrm{kV}$ load area on 2-Buses System and 10-Buses system. The voltage instability predictor calculates the power margin and makes comparison to the pre-set margin threshold. The stability of the system is then justified by comparing the margin and pre-set threshold.

This study is organized into five sections. Background of study is provided in section 2 . Selections of methods are described in section 3 . Results are provided and discussed in section 4. Finally, the significant conclusions for this study are concluded in section 5 .

\section{BACKGROUND OF STUDY}

\subsection{Wide area Measurement System (WAMS) in Malaysia}

PMUs are increasingly being used as a major technology enable of the Wide Area Monitoring, Protection and Control (WAMPAC) system. PMUs are the most accurate and advanced time-synchronized technology, which provides voltage and current phasor and frequency information, synchronized with high precision to a common time reference provided by the Global Positioning System (GPS).

With the installation of PMUs eventually make a transition from a conventional SCADA-based measurement system to a more advance measurement system that will utilize synchronized measurements from geographically distant locations and increase the situational awareness by monitoring a wide area of the power system in real time (Minhat, 2008).

Meanwhile, the introduction of the Wide Area Monitoring System (WAMS) with PMU simulator was undertaken by TNB-R (Abdullah and Yusuf, 2008). The main objective was to build a reliable and accurate widearea measurement system for Wide-Area Monitoring, Control and Protection R\&D program to assist TNB to improve and secure the grid. The TNB WAMS system architecture is shown in Fig. 1. 


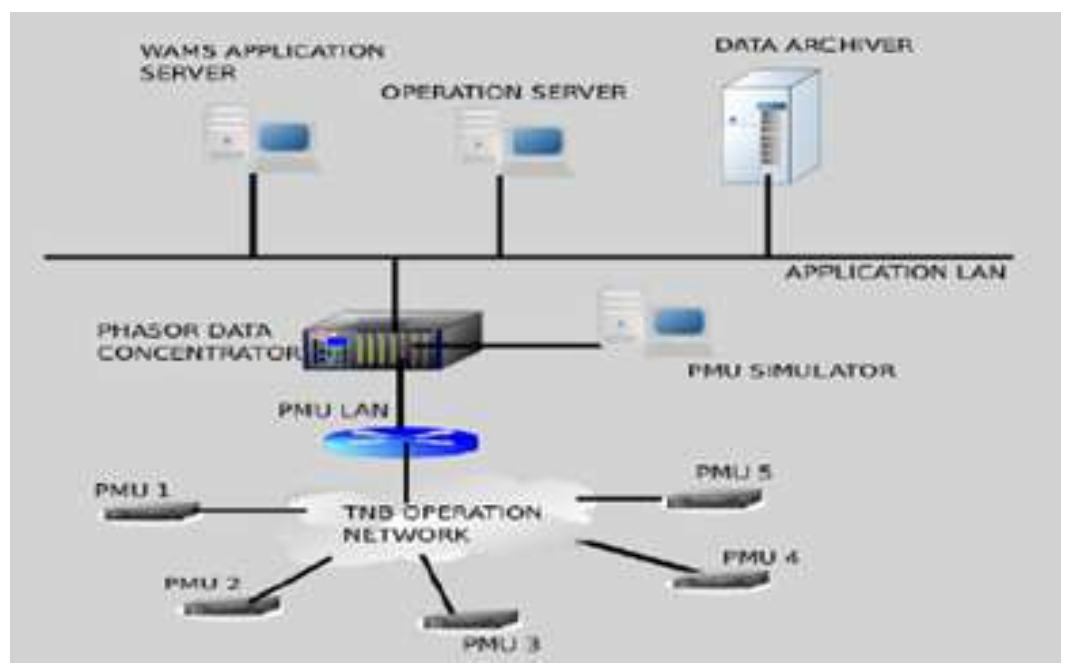

Fig. 1. Tenaga Nasional Berhad (TNB) wide Area Measurement System (WAMS) architecture

\subsection{Methods for Voltage Stability Analysis}

Voltage stability is continuous issues despite various researches were conducted a couple of decades ago. Several voltage collapse events initiated by voltage instability was reported in many parts of the globe (Lee and Lee, 1991). One of the local issues experienced in Malaysia is the major blackout event on 13 January 2005; which finally forced the local authority to shed some of the loads to balance the generation and distribution demands (Vaiman et al., 2012). Many different analysis methods were proposed in the literature aiming to provide a better understanding of the phenomenon; to evaluate the systems operating conditions and to come up with appropriate control measures to keep systems from experiencing voltage instability situations.

\subsubsection{P-V curve Method}

This method is most widely used methods of voltage stability analysis. It gives the available amount of active power margin before the point of voltage instability (Taylor, 1994). A major disadvantage is that the power flow simulation will diverge near the nose or maximum power point on the curve. Another disadvantage is that generation must be realistically rescheduled as the area load is increased. Most importantly, the P-V curves are dynamics in real time, which mean that the curve will not be static (Warland and Holen, 2001).

\subsubsection{Voltage Instability Predictor (VIP++) Method}

This method used local measurement from simulated PMUs data to predict the distance to voltage collapse. VIP method was based on the assumption that voltage instability is closely related to a maximum load ability of a transmission network, thus the Thevenin impedance is equal to the apparent load impedance (Warland and Holen, 2001).

\subsection{Voltage Stability Indicator}

Many utilities company operation criterion still based on the magnitude of bus voltages. However, the voltage level is inadequate for voltage stability because the phenomenon is typically influenced by several other factors such as loading conditions, faults and reactive power resources (Canizares, 2002). In real world, it is impractical to compute the actual P-V curve of a dynamic system in real-time. Therefore, it is a greatest challenge to determine the under voltage relay setting in order to protect the system from voltage instability occurrences. A new technique to predict the behaviour of the system by treating the system as Thevenin equivalent network was proposed by ( Vu et al., 1999) with some modification is being used as one of the method in this research.

The maximum power transfer is simply determined based on voltage stability margin $\left(\overline{\mathrm{E}_{\mathrm{th}}}-\overline{\mathrm{V}_{\mathrm{th}}}\right) *$ and by the ratio of the load impedance to the Thevenin 
impedance $\left|Z_{\text {th }}\right|=\left|Z_{\mathrm{L}}\right|$ by referring to (Soliman et al., 2003; Tsai and Wong, 2008). In summary,

Maximal power transfer Equation 1:

$$
\overline{\mathrm{V}}=\overline{\mathrm{E}_{\mathrm{th}}}-\overline{\mathrm{V}_{\mathrm{L}}}
$$

Where:

$\overline{\mathrm{V}} \quad=$ Voltage stability margin

$\overline{\mathrm{E}_{\mathrm{th}}}=$ Vector of Thevenin voltage

$\overline{\mathrm{V}_{\mathrm{L}}}=$ The vector of voltage at local bus

Maximal power transfer Equation 2:

$$
\left|\overline{\mathrm{Z}_{\mathrm{L}}}\right|=\left|\overline{\mathrm{Z}_{\mathrm{th}}}\right|
$$

Where:

$$
\begin{aligned}
& \left|\overline{Z_{L}}\right|=\text { Vector of load impedance } \\
& \left|\overline{Z_{\text {th }}}\right|=\text { Vector of Thevenin impedance }
\end{aligned}
$$

The method of voltage instability load shedding using a local measurement unit was proposed by (Zhang et al., 2012). While, the extension work which expressing the indicators in terms of the system critical voltage and maximum power that can be transmitted to the load provide meaningful interpretation to the system operators (Vu et al., 2001). In this study, voltage stability indicator method is adopted as one of the techniques with some modification to investigate the voltage instability phenomenon in the TNB network.

\section{SELECTION OF METHODS}

\subsection{Implementation of Radial Equivalent Independent (REI) Network}

Due to major increasing power demand nowadays, power systems can be classified into large or very large systems, with a high degree of interconnectivity. Hence, the complexity of the power systems created a big challenge to the power system engineers to simplify the network for efficient system analysis (Gavrilas et al., 2008).

By implementing of REI network, the analysis can be simplified by decreasing the size of the system to few nodes. Wide Area Power Systems (WAPS) are divided into three subsystems, which are Internal Power System (IPS), External Power System (EPS) and boundary power system or Boundary Nodes (BNs) as shown in Fig. 2.
The general circuit of REI network is shown in Fig. 3. The number of bus is denoted by "N". The voltage and current denoted by $\mathrm{V}$ and $\mathrm{I}$ at the bus are respectively measured by PMUs. Besides, notation of $S$ is representing the power transfer from the load centre. The $V_{G}$ and $V_{R}$ are represented by the ground bus voltage and fictitious bus voltage. The branch admittance is denoted by $\mathrm{Y}$.

Based on nodal analysis, $S_{R}$ and $I_{R}$ which is the total sum of apparent power and current to the load, respectively, can be calculated by Equation 3:

$\mathrm{S}_{\mathrm{R}}=\sum \mathrm{S}_{\mathrm{N}}=\mathrm{S}_{1}+\mathrm{S} 2+\ldots+\mathrm{S}_{\mathrm{N}}$

where, $S_{R}$ is the fictitious bus apparent power Equation 4:

$\mathrm{IR}_{\mathrm{R}}=\sum \mathrm{IN}=\mathrm{I}_{1}+\mathrm{I}_{2}+\ldots+\mathrm{I}_{\mathrm{N}}$

where, $I_{R}$ is the fictitious bus current

Therefore, the fictitious bus voltage and the branch admittance can be calculated by using Equation 5 and 6:

$\mathrm{V}_{\mathrm{R}}=\frac{\mathrm{S}_{\mathrm{R}}}{\mathrm{IR}^{*}}$

Where:

VR = The fictitious bus voltage

$\mathrm{SR}=$ The fictitious bus apparent power

$\mathrm{IR}=$ The fictitious bus current

$\mathrm{Y}_{\mathrm{R}}=\frac{\mathrm{IR}_{\mathrm{R}}}{\mathrm{V}_{\mathrm{R}}}$

Where:

$\mathrm{YR}=$ The branch admittance

$\mathrm{IR}=$ The fictitious bus current

VR $=$ The fictitious bus voltage

\subsection{State Estimation Using the Discrete Kalman Filter (DKF)}

Thevenin equivalent network is shown in Fig. 4. The tracking process for the Thevenin equivalent is the most important for the voltage collapse detection. There are many methods to track the Thevenin parameters were applied previously. Five methods, including Cartesian coordinates, least square method, delta method, cumulative sum filter and polar coordinates were summarized by (Warland and Holen, 2001). 

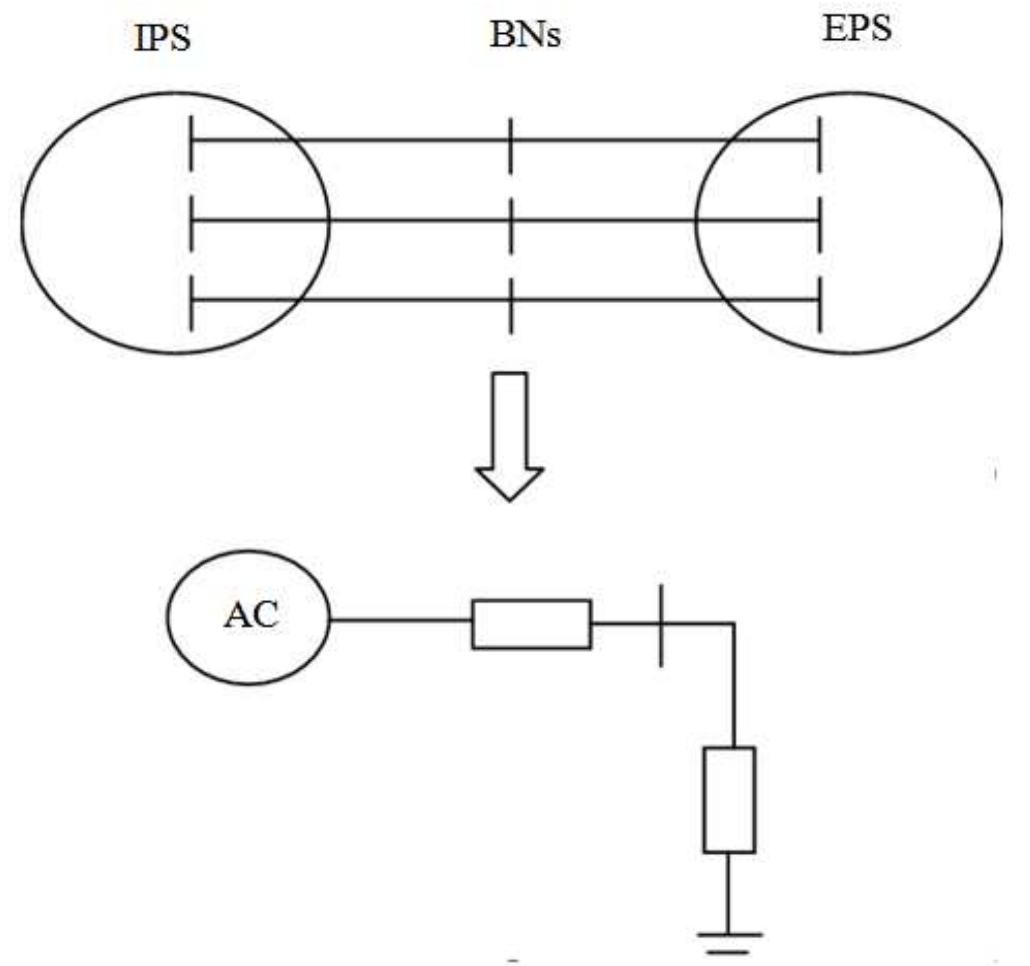

Fig. 2. WAPS and the simplified network system

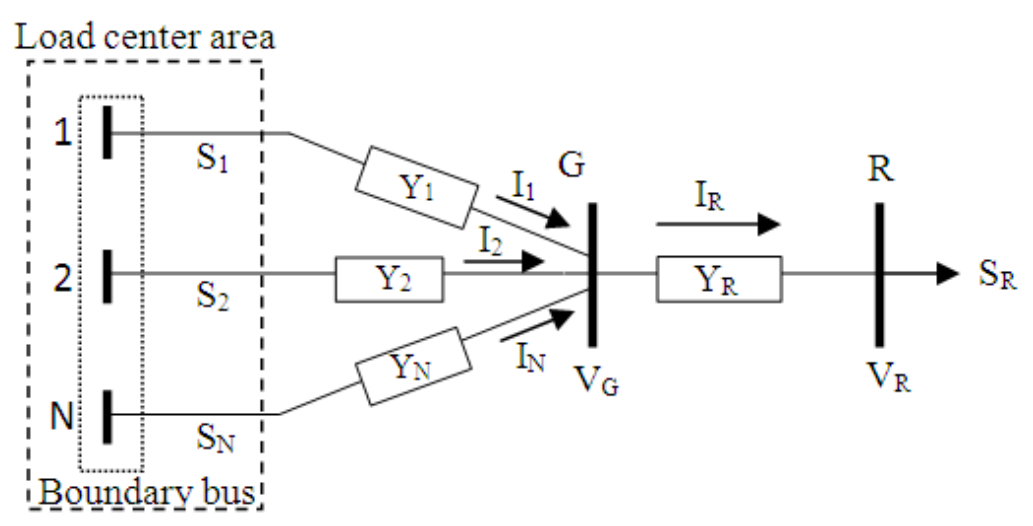

Fig. 3. General circuit of REI network

Application of Kalman filter method has become a popular technique discussed in several papers by ( $\mathrm{Vu}$ et al., 1999; Warland and Holen, 2001; Zhang et al., 2012) due to the accuracy and stability to track the Thevenin parameters.

By applying Kirchhoff's Voltage Law (KVL) on the Thevenin equivalent of the system at Bus $\mathrm{Z}$ in Fig. 4 can be expressed by Equation 7 (Al-Ammari, 2002):

$$
\mathrm{E}_{\mathrm{TH}}=\mathrm{V}_{\mathrm{L}}+\left(\mathrm{Z}_{\mathrm{TH}}{ }^{*} \mathrm{I}_{\mathrm{L}}\right)
$$

Where:

$\mathrm{ETH}=$ Thevenin voltage seen by Bus Z

$\mathrm{VL}=$ The voltage of Bus $\mathrm{Z}$

ZTH = The Thevenin's equivalent impedance at Bus Z

IL = The load current connected to the Bus Z 


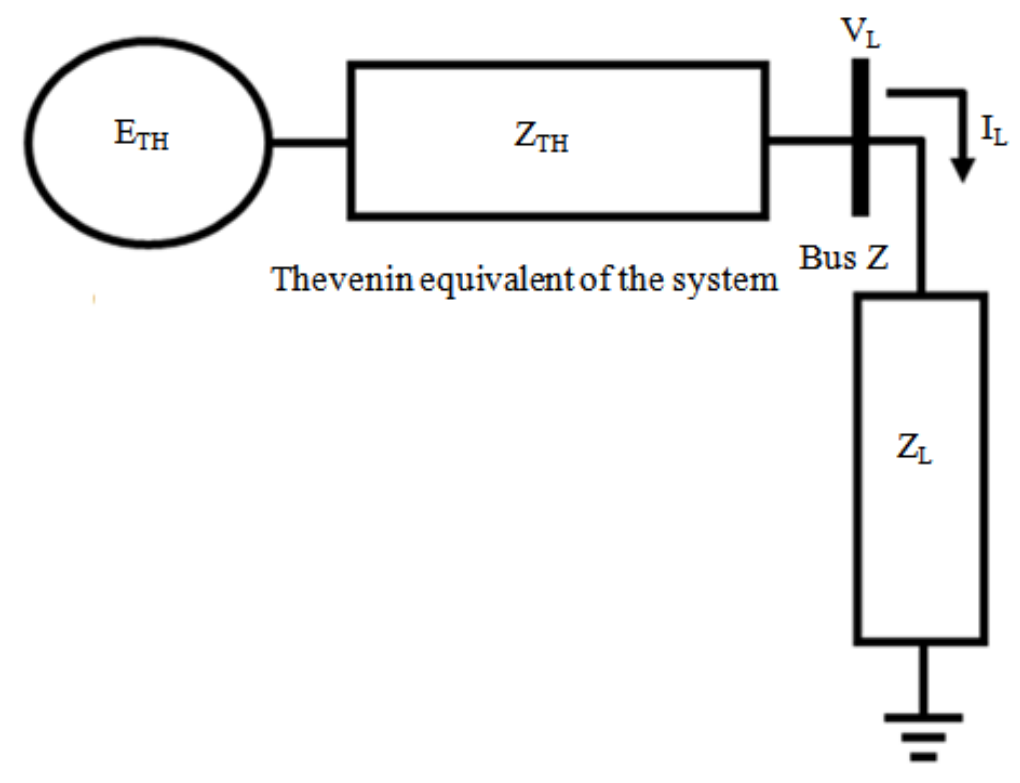

Fig. 4. Thevenin equivalent network

The voltage and load current connected to the Bus Z is represented in vector forms are shown in Equation 8 and 9:

$$
\begin{aligned}
& \overrightarrow{\mathrm{V}_{\mathrm{L}}}=\mathrm{V}_{\text {real }}+j \mathrm{~V}_{\text {imaginary }}=\mathrm{V}_{\mathrm{L}} \angle \alpha \\
& \overrightarrow{\mathrm{IL}_{\mathrm{L}}}=\mathrm{I}_{\text {real }}+\mathrm{jI}_{\text {imaginary }}
\end{aligned}
$$

\section{Where:}

$\overline{\mathrm{V}}=$ The vector of voltage

$\mathrm{V}$ real $=$ The real voltage of the complex number

$\mathrm{V}_{\text {imaginary }}=$ The imaginary voltage of complex number

VL $=$ The magnitude voltage of the complex number

a $=$ The voltage angle of the complex number

$\overrightarrow{\mathrm{I}_{\mathrm{L}}} \quad=$ The vector of current flow to the load

Ireal $=$ The real current of the complex number

$\mathrm{I}_{\text {imaginary }}=$ The imaginary current of the complex number

Meanwhile, the load impedance in terms of vector is shown in Equation 10:

$\overrightarrow{Z_{L}}=R_{L}+j X_{L}=Z_{L} \angle \phi$

Where:

$\overrightarrow{\mathrm{Z}_{\mathrm{L}}}=$ Vector of load impedance
$\mathrm{RL}=$ The real resistance on the load of the complex number

$\mathrm{XL}=$ Imaginary reactance on the load of the complex number

$\mathrm{ZL}=$ The magnitude of the load impedance

$\phi \quad=$ The angle of phi of the load impedance

Thevenin voltage and impedance can be represented as a vector in Equation 11 and 12.

$$
\begin{aligned}
& \overrightarrow{\mathrm{ETH}}=\mathrm{E}_{\text {real }}+\mathrm{j} \mathrm{E}_{\text {imaginary }}=\mathrm{ETH}_{\mathrm{TH}} \angle \delta \\
& \overrightarrow{\mathrm{ZTH}}=\mathrm{RTH}_{\mathrm{TH}}+\mathrm{j} \mathrm{XTH}_{\mathrm{TH}}=\mathrm{ZTH}_{\mathrm{TH}} \angle \beta
\end{aligned}
$$

Where:

$\overrightarrow{\mathrm{ETH}}=$ Vector of Thevenin voltage

$\mathrm{E}_{\text {real }} \quad=$ The real voltage of the complex number

$\mathrm{E}_{\text {imaginary }}=$ The imaginary voltage of complex number

ETH = The magnitude Thevenin of voltage complex number

$\delta=$ Magnitude current of the complex number

$\overrightarrow{\mathrm{ZTH}} \quad=$ Vector of Thevenin impedance

RTH = The real resistance on the Thevenin system of the complex number

$\mathrm{X}_{\mathrm{TH}} \quad=$ The imaginary reactance on the Thevenin system of the complex number

$\mathrm{Z}_{\mathrm{TH}} \quad=$ The magnitude of the Thevenin impedance 
$\mathrm{P}_{\max }=$ Maximum real power transfer

$\mathrm{E}_{\mathrm{TH}}=$ Magnitude of Thevenin voltage

By separating the real and imaginary parts, the equation can be formed in rectangular form as provided in Equation 13:

$$
\left[\begin{array}{c}
\mathrm{V}_{\text {real }} \\
\mathrm{V}_{\text {imaginary }}
\end{array}\right]=\left[\begin{array}{cccc}
1 & 0 & -\mathrm{I}_{\text {real }} & \mathrm{I}_{\text {imaginary }} \\
0 & 1 & -\mathrm{I}_{\text {imaginary }} & -\mathrm{I}_{\text {real }}
\end{array}\right]\left[\begin{array}{c}
\mathrm{E}_{\text {real }} \\
\text { Eimaginary } \\
\mathrm{R}_{\text {th }} \\
\mathrm{X}_{\text {th }}
\end{array}\right]
$$

Equation 13 is valid at any load bus on the system. In vector form and Equation 13 can be written as Equation 14:

$$
\widehat{Z}=(H * \widehat{X})+\widehat{V}
$$

\section{Where:}

$\hat{\mathrm{Z}}=\mathrm{A}$ 2-by-1 matrix voltage components vector

$\widehat{\mathrm{X}}=\mathrm{A}$ 4-by-1 state vector matrix to be identified

$\mathrm{H}=\mathrm{A}$ 2-by-4 observation matrix

$\widehat{\mathrm{V}}=\mathrm{A}$ 2-by-1 associated error matrix vector to be minimized

An estimation method using Kalman Filter is therefore developed. According to (Bishop and Welch, 2001), Kalman Filter can be divided into two, which are Discrete Kalman Filter (DKF) and Extended Kalman Filter (EKF). DKF method is implemented in this research. The DKF complete operation is shown in Fig. 5.

Where:

$\widehat{X} \bar{k}=$ The "prior estimate" (rough estimate before the measurement update correction)

$\mathrm{P} \overline{\mathrm{k}}=$ The "prior error covariance

$\widehat{\mathrm{X}} \mathrm{k}=$ Estimate the $\mathrm{x}$ at time $\mathrm{k}$

$\mathrm{Pk}=$ necessary for $\mathrm{k}_{1}$ (future) estimate together with $\widehat{\mathrm{x}_{\mathrm{k}}}$

$\mathrm{Kk}=$ Kalman gain

\subsection{Calculation for Maximum Power Transfer and Power Margin}

From Thevenin equivalent network in Fig. 4, the maximum power transfer and critical voltage can be formulated as below (Foo, 2009).

The maximum real power transfer can be calculated by Equation 15:

$$
\mathrm{P}_{\max }=\frac{\mathrm{ETH}^{2}}{\mathrm{ZTH}_{\mathrm{TH}} *[2(1+2 \cos (\beta-\phi))]} * \cos \theta
$$

Where:

$\beta=$ The angle of Thevenin impedance

$\phi \quad=$ The angle of Load impedance

$\theta \quad=$ The (angle of bus voltage-angle of bus current)

The maximum reactive power transfer is Equation 16:

$\mathrm{Q}_{\max }=\frac{\mathrm{ETH}^{2}}{\mathrm{Z}_{\mathrm{TH}} *[2(1+2 \cos (\beta-\phi))]} * \sin \theta$

Where:

$\mathrm{Q}_{\max }=$ Maximum reactive power transfer

$\mathrm{E}_{\mathrm{TH}}=$ Magnitude of Thevenin voltage

$\mathrm{Z}_{\mathrm{TH}}=$ The magnitude of Thevenin impedance

$\beta=$ The angle of Thevenin impedance

$\phi \quad=$ The angle of Load impedance

$\theta \quad=$ The (angle of bus voltage-angle of bus current)

Power margin can be calculated from the different between maximum power transfer and the power transfer to the load as.

The real power margin Equation 17:

$\mathrm{P}_{\operatorname{marg} \text { in }}=\mathrm{P}_{\max }-\mathrm{PL}$

Where:

$\mathrm{P}_{\text {margin }}=$ Real power margin

$\mathrm{P}_{\max } \quad=$ Maximum real power transfer

$\mathrm{PL} \quad=$ Real power at the load

The reactive power margin Equation 18:

$\mathrm{Q}_{\mathrm{m} \arg \text { in }}=\mathrm{Q}_{\max }-\mathrm{Q}_{\mathrm{L}}$

Where:

$\mathrm{Q}_{\mathrm{m} \text { argin }}=$ Reactive power margin

$\mathrm{Q}_{\max }=$ Maximum reactive power transfer

$\mathrm{Q}_{\mathrm{L}} \quad=$ Reactive power at the load

The apparent power margin Equation 19:

$\mathrm{S}_{\mathrm{marg} \text { in }}=\mathrm{S}_{\max }-\mathrm{S}_{\mathrm{L}}$

Where:

$\mathrm{S}_{\text {margin }}=$ Apparent power margin

$\mathrm{S}_{\max }=$ The maximum apparent power transfer

$\mathrm{S}_{\mathrm{L}} \quad=$ Apparent power at load 


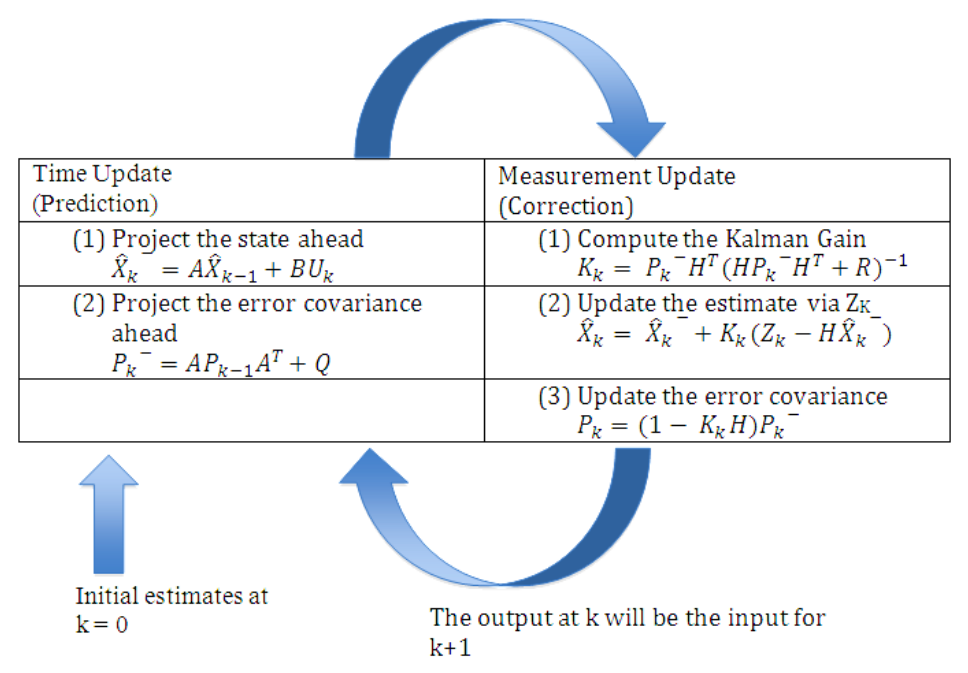

Fig. 5. A complete picture of the operation of the Discrete Kalman Filter (DKF)

Besides, with the predicted Thevenin parameters, $Z_{\text {th }}$ values are achieved. While, $Z_{\mathrm{L}}$ can be obtain by using the PMUs data. According to (Vu et al., 1999), voltage collapse will occur when Equation 20:

$$
\mathrm{Z}_{\mathrm{TH}}=\mathrm{Z}_{\mathrm{L}}
$$

Where:

$\mathrm{Z}_{\mathrm{TH}}=$ The Thevenin impedance

$Z_{\mathrm{L}}=$ The load impedance

By having the estimated Thevenin impedance value, the minimum magnitude of the load impedance in a stable system can be defined. Hence, the early warning index can be defined in Equation (21) to monitor the condition on the power system:

$$
\text { Indeximpedance }=\frac{\left|\mathrm{Z}_{\mathrm{TH}}\right|}{\left|\mathrm{ZL}_{\mathrm{L}}\right|}
$$

More power will be drawn whenever the load impedance started to drop. By this, the early warning index also decreases indicating that the system is an edge near to the nose point of voltage collapse. The index is soon approaching 1 when the system is operating at the nose point. The main perception is to ensure the index should always stay less than 1 and suitable early prevention methods should be implemented when the index is getting closer to 1 (Foo, 2009).

\section{SIMULATION RESULTS AND DISCUSSION}

For more detailed analysis, the application is tested with simulation data from Real-time Digital Simulator (RTDS). This is to ensure that voltage instability would occur in the specified load area and in the meantime to estimate the performance of RTVSM application when the system is exposed voltage instability phenomena.

\subsection{Application to TNB $132 \mathrm{kV}$ Network (2 Bus System)}

The analysis will be performed in one of the TNB load areas to examine the effectiveness of the voltage stability margin for 2 bus system. The $132 \mathrm{kV}$ network of the area under investigation is shown in Fig. 6, where the incoming $275 \mathrm{kV}$ supply is taken from Bus 1 and stepped down to $132 \mathrm{kV}$ by two 180 MVA transformers, which connected to Bus 1 and Bus 2. All buses in this area are considered as the load bus. Load bus can be defined as transmission line feeding a certain load. However, this application will only consider Bus 5, Bus 6, Bus 7, Bus 8, Bus 9 and Bus 10 as the load centre.

Total load in the area is about 85 MVA and the power flows to the load centre are through Bus 5 and Bus 10. Two PMUs are installed to monitor voltage and current phasor at Bus 5 and Bus 10. This area was previously a rural area with very low load demand. However, loads have recently grown dramatically due to development of infrastructures and industrial estates.

The network is a ring network with the total line length almost $300 \mathrm{~km}$. 


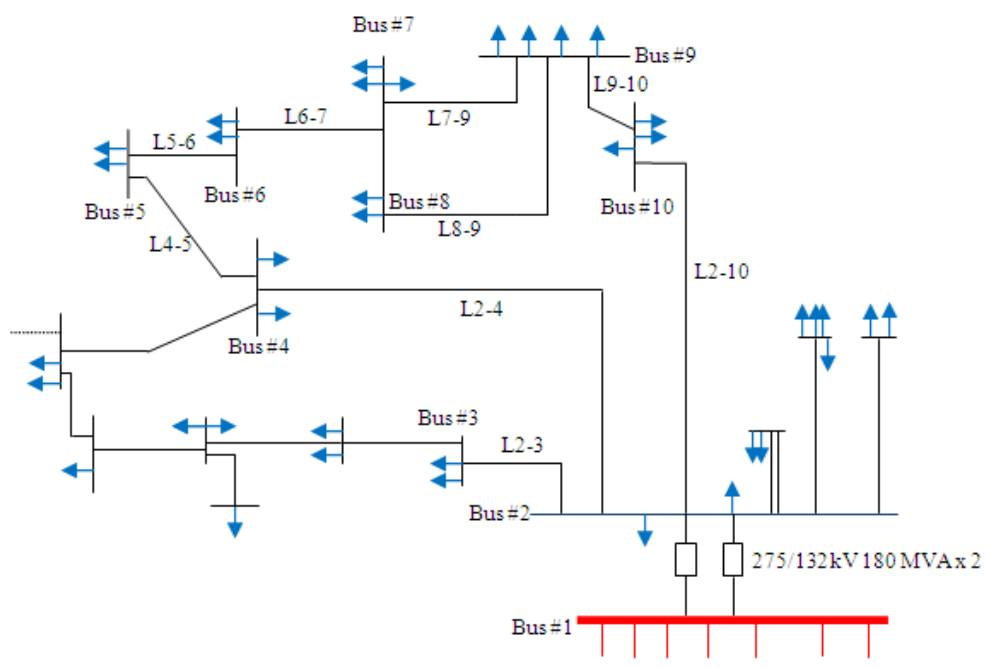

Fig. 6. Detail of TNB $132 \mathrm{kV}$ load area under investigation

However, the network may become a long radial network if the line in L2-10 of the network is out of service. The worst contingency is when L2-10 is tripped. The transmission lines feeding the area will be facing severe overload and low voltage problem at the receiving end point, which is Bus 10.

\subsection{Application to TNB $132 \mathrm{kV}$ Network (10 Bus System)}

The analysis will be performed in one of the TNB load areas to examine the effectiveness of the voltage stability margin for 10 bus system. All buses in this area are considered as the load bus. However, this application will only consider Bus 1, Bus 2, Bus 3, Bus 4, Bus 5, Bus 6, Bus 7, Bus 8, Bus 9 and Bus 10 as the load centre. Ten PMUs are installed to monitor voltage and current phasor at Bus 1, Bus 2, Bus 3, Bus 4, Bus 5, Bus 6, Bus 7, Bus 8, Bus 9 and Bus 10.

\subsection{Case A: Results and Analysis for 2 Buses System}

The voltage measurements and apparent power transfer at Bus 5 and Bus 10 by the simulated PMUs data during fault occurrence at $23.94 \mathrm{sec}$ are shown in Table 1. By tripping of Bus 10 with ground fault is simulated followed by gradual increments of the demand at each bus after $23.94 \mathrm{sec}$ as shown in Table 1. As expected, the voltage drops when the load is increased, which can be observed in Fig. 7 and 8.

After the line tripping at Bus 10, the power flow of Bus 10 drops to nearly zero as shown in Fig. 9. Therefore, at that moment just only Bus 5 carries the power flow to the load centre at that moment as shown in Fig. 10.

The magnitudes of the measured load impedance and the estimated Thevenin impedance are shown in Fig. 11. The magnitude of load impedance decreases with the gradual load increment approaching the magnitude of Thevenin impedance. The simulation started in a normal state without any occurrence until $23.94 \mathrm{sec}$ where Bus 10 was tripped and causing the sharp rise of the Thevenin impedance while load impedance decreases.

Clearly from Table 2 that the two impedances, load and Thevenin almost come together at the point of collapse during $634.10 \mathrm{sec}$. They are, however, not becoming exactly equal because the Thevenin value is estimated and thus lags in the true value (the method involves a moving window). Nevertheless, the fact that two impedances are heading toward each other is evidence that Equation 20 holds.

From the observation in Table $3, \mathrm{P}_{\mathrm{L}}$ and $\mathrm{P}_{\max }$ sharing the same value which is 1.493 p.u. at $634.10 \mathrm{sec}$, which is the same as the point where the load impedance crossing the Thevenin impedance.

Besides, the real power margin based on the difference between real power transfer and the limit is shown in Fig. 12. The real power margin is approaching zero at $634.1 \mathrm{sec}$ in Table 4, which means that the system is on beyond the limit of voltage instability beginning. Operators at the utilities company are able to determine the status of the system based on the margin which roles as an indicator. After $634.1 \mathrm{sec}$ in Fig. 12, the graph is no longer valid since the power flow solution after a voltage collapse diverges. 
Goh, H.H. et al. / American Journal of Applied Sciences 11 (5): 717-731, 2014

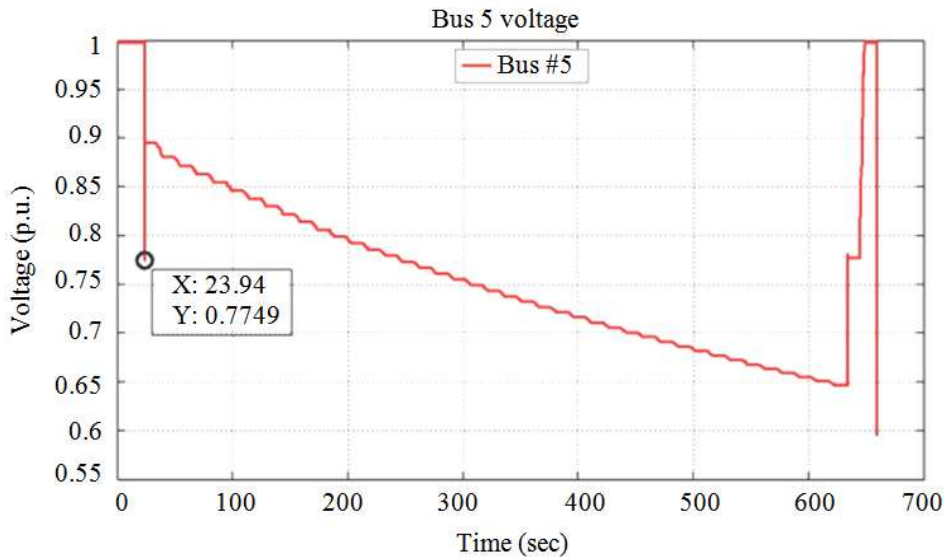

Fig. 7. Bus 5 voltage measurements

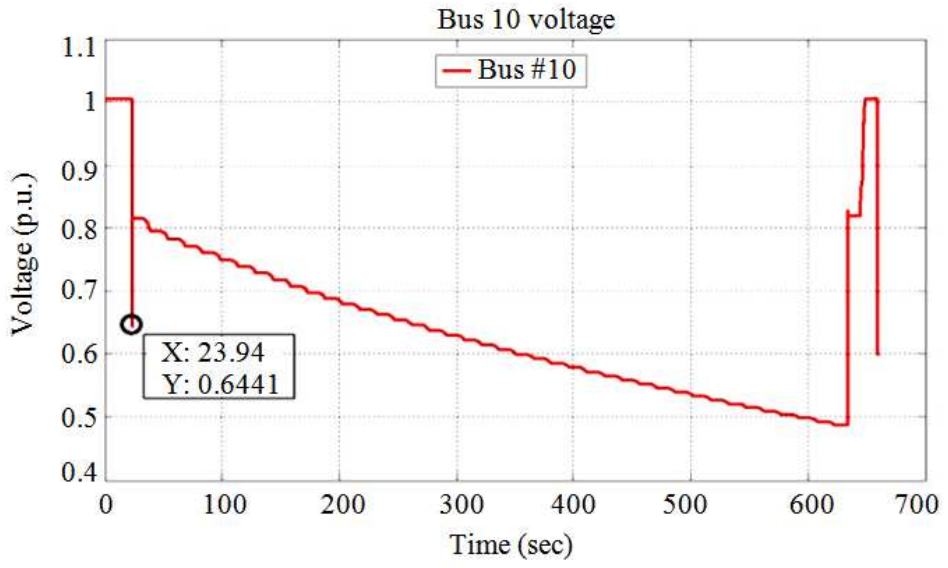

Fig. 8. Bus 10 voltage measurements

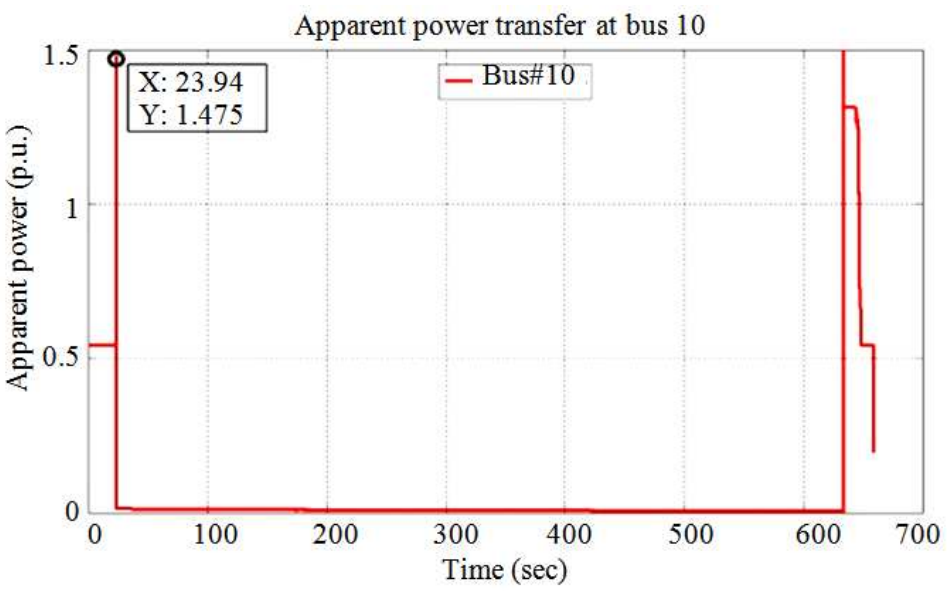

Fig. 9. Bus 10 apparent power 
Goh, H.H. et al. / American Journal of Applied Sciences 11 (5): 717-731, 2014

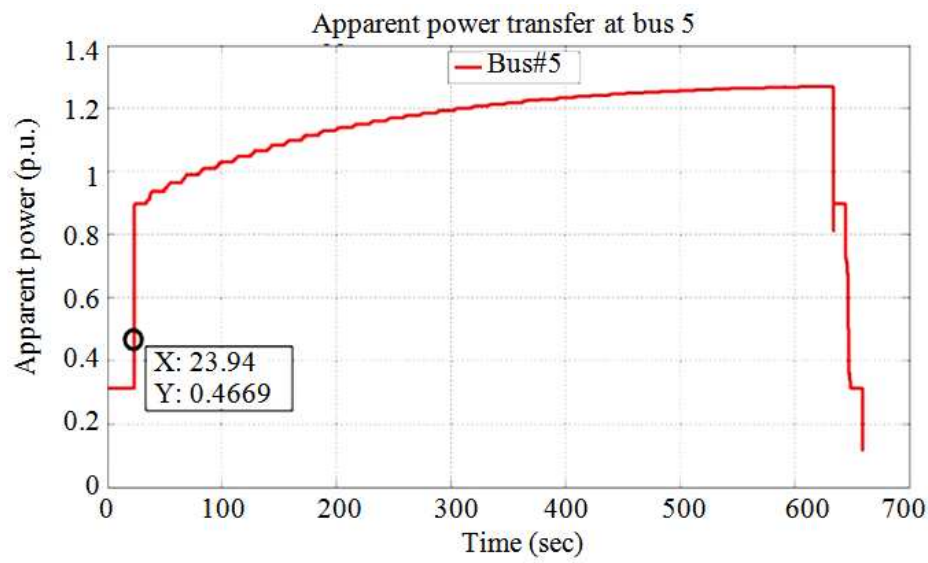

Fig. 10. Bus 5 apparent power

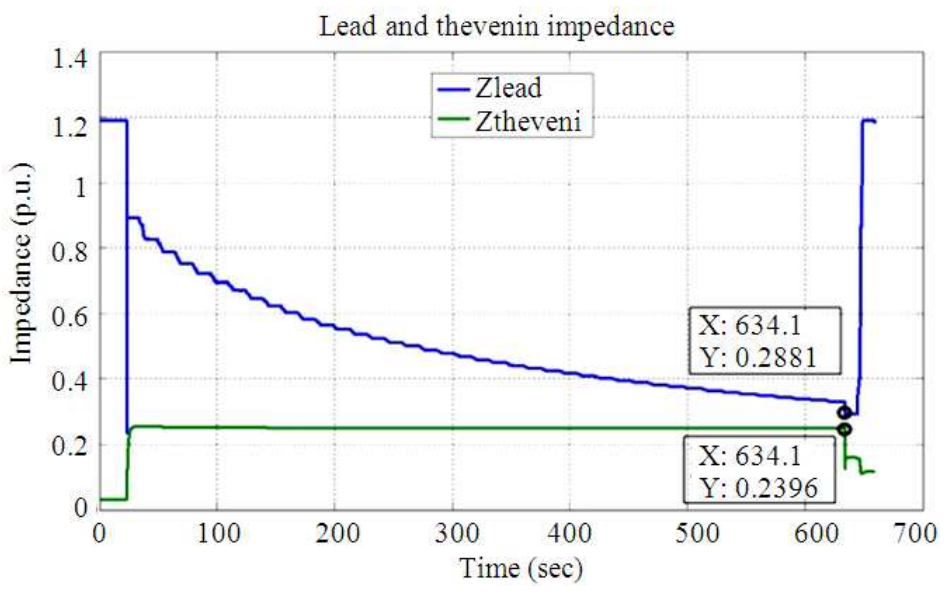

Fig. 11. Load impedance and Thevenin impedance merge at the point of collapse

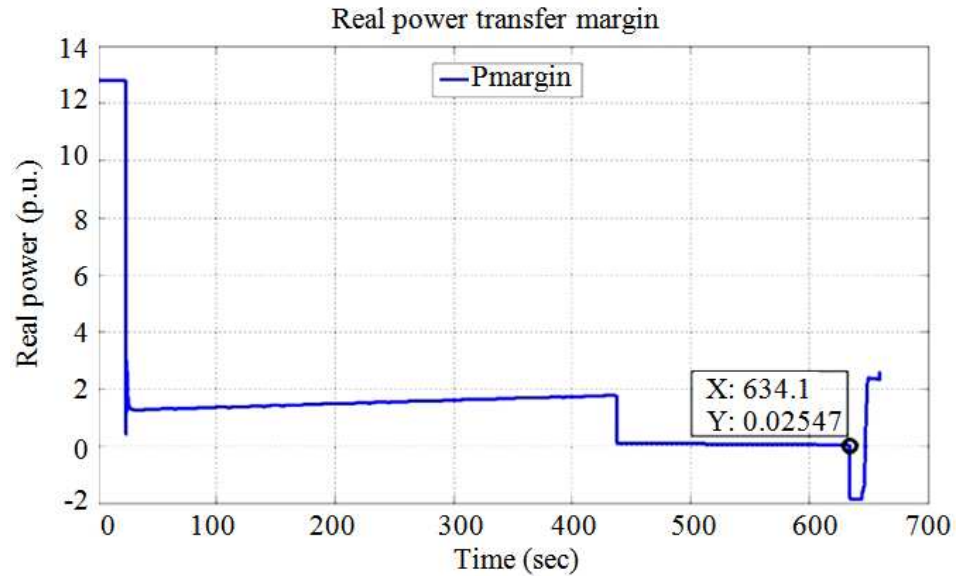

Fig. 12. Real power margin between the transfer and the load 


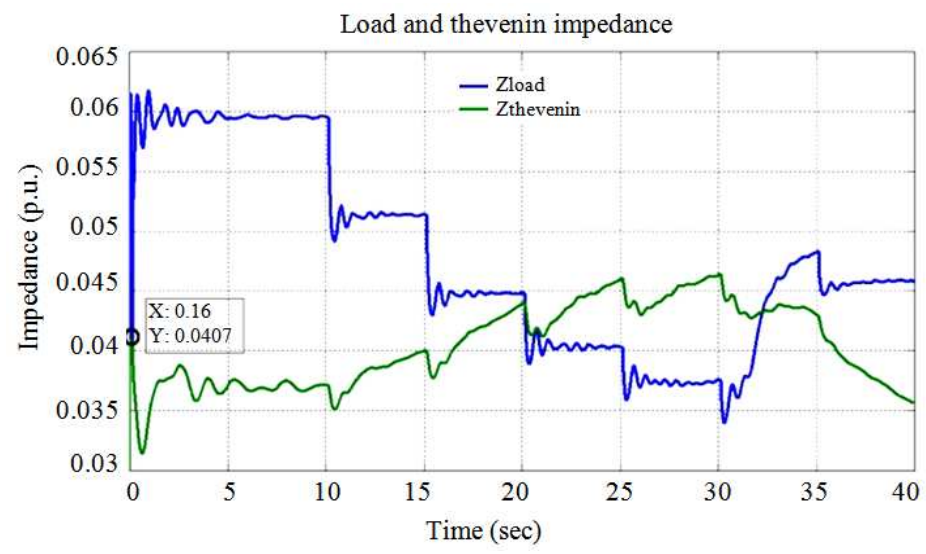

Fig. 13. Load impedance and Thevenin impedance merge at the point of collapse

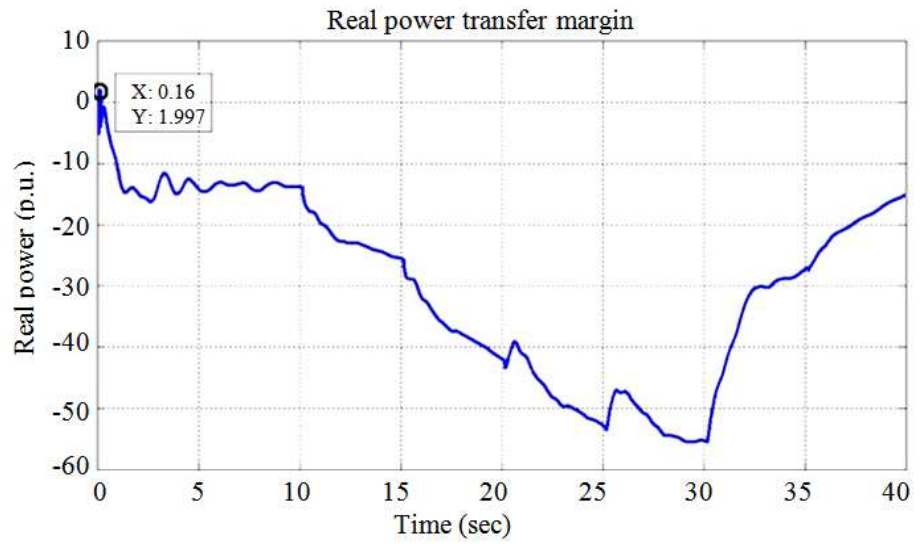

Fig. 14. Real power margin between the transfer and the load

Table 1. The bus voltage and power transfer during fault occurred at $23.94 \mathrm{sec}$

\begin{tabular}{lll}
\hline $\begin{array}{l}\text { Number of bus } \\
\text { Bus number }\end{array}$ & $\begin{array}{l}\text { Voltage fault } \\
\text { Voltage (p.u.) }\end{array}$ & $\begin{array}{l}\text { Power transfer } \\
\text { Apparent power (p.u.) }\end{array}$ \\
\hline 5 & 0.7749 & 0.4669 \\
10 & 0.6441 & 1.4750 \\
\hline
\end{tabular}

Table 2. Voltage collapse occurrence at $634.10 \mathrm{sec}$ when load impedance crossing Thevenin impedance and load voltage crossing Thevenin voltage

\begin{tabular}{ll}
\hline Type of impedance & Impedance (p.u.) \\
\hline Load impedance $\left(\mathrm{Z}_{\mathrm{L}}\right)$ & 0.7749 \\
Thevenin impedance $\left(\mathrm{Z}_{\mathrm{th}}\right)$ & 0.6441 \\
\hline
\end{tabular}

Table 3. Real power transfer and limit when the system tends to collapse at $634.1 \mathrm{sec}$

\begin{tabular}{ll}
\hline Real power transfer & Real power (p.u.) \\
\hline Real power $\left(\mathrm{P}_{\mathrm{L}}\right)$ & 1.493 \\
Maximum Power $\left(\mathrm{P}_{\max }\right)$ & 1.493 \\
\hline
\end{tabular}

Table 4. Real power margin between maximum power and real power

\begin{tabular}{ll}
\hline Real power margin & Real power (p.u.) \\
\hline Power margin $\left(\mathrm{P}_{\text {margin }}\right)$ & 0.02547 \\
\hline
\end{tabular}

\subsection{Case B: Results and Analysis for 10 Buses System}

By tripping the line at Bus 3 with ground fault is simulated followed by gradual increment of the demand at each load bus after $0.1 \mathrm{sec}$. The voltage increments at Bus 1, Bus 2, Bus 3, Bus 4, Bus 5, Bus 6, Bus 7, Bus 8, Bus 9 and Bus 10 by the simulated PMUs data are listed in Table 5. After the line tripping at Bus 3, the power flow of Bus 3 drops to nearly zero as shown in Table 5 . Therefore, at that moment just left Bus 1, Bus 2, Bus 4, Bus 5, Bus 6, Bus 7, Bus 8, Bus 9 and Bus 10 carry the power flow to the load centre at that moment. 
The magnitudes of the measured load impedance and the estimated Thevenin impedance are shown in Fig. 13. The magnitude of load impedance decreases with the gradual load increment approaching the magnitude of Thevenin impedance. The simulation started in a normal state without any occurrence until $0.1 \mathrm{sec}$ where Bus 3 was tripped and causing the sharp rise of the Thevenin impedance while load impedance decreases. In Table 6, the load and Thevenin impedance come together during $0.16 \mathrm{sec}$ at the point of 0.0407 p.u.

From Fig. 13, the evidence shown that voltage collapse happened when load impedance crossing the Thevenin impedance. Once again, it is proven that the Equation 20 hold strongly.

From the observation in Table 7, $\mathrm{P}_{\mathrm{L}}$ and $\mathrm{P}_{\max }$ sharing the same value which is 16.44 p.u. at $0.16 \mathrm{sec}$, which is the same as the point where the load impedance crossing the Thevenin impedance.

The real power margin based on the difference between real power transfer and the limit is shown in Fig. 14. From the observation, the point of collapse is at $0.16 \mathrm{sec}$, which is the same as the point where load impedance crossing the Thevenin impedance.

Table 5. The bus voltage and power transfer during fault occurred at $0.1 \mathrm{sec}$

\begin{tabular}{lll}
\hline $\begin{array}{l}\text { No. of bus } \\
\text { Bus number }\end{array}$ & $\begin{array}{l}\text { Voltage fault } \\
\text { Voltage (p.u.) }\end{array}$ & $\begin{array}{l}\text { Power transfer } \\
\text { Apparent power (p.u.) }\end{array}$ \\
\hline 1 & 0.873 & 3.006 \\
2 & 0.295 & 1.054 \\
3 & 0.000 & 0.000 \\
4 & 0.644 & 0.342 \\
5 & 0.689 & 2.876 \\
6 & 0.689 & 2.432 \\
7 & 0.711 & 0.457 \\
8 & 0.711 & 0.312 \\
9 & 0.774 & 0.743 \\
10 & 0.774 & 0.627 \\
\hline
\end{tabular}

Table 6. Voltage collapse occurrence at $0.16 \mathrm{sec}$ when load impedance crossing Thevenin impedance and load voltage crossing Thevenin voltage

\begin{tabular}{ll}
\hline Type of impedance & Impedance (p.u.) \\
\hline Load impedance $\left(\mathrm{Z}_{\mathrm{L}}\right)$ & 0.0407 \\
Thevenin impedance $\left(\mathrm{Z}_{\mathrm{th}}\right)$ & 0.0407 \\
\hline
\end{tabular}

Table 7. Real power transfer and limit when the system tends to collapse at $0.16 \mathrm{sec}$

\begin{tabular}{ll}
\hline Real power transfer & Real power (p.u.) \\
\hline Real power $\left(\mathrm{P}_{\mathrm{L}}\right)$ & 16.44 \\
Maximum Power $\left(\mathrm{P}_{\max }\right)$ & 16.44 \\
\hline
\end{tabular}

Besides that, the real power margin is approaching zero at $0.16 \mathrm{sec}$, which means that the system is on beyond the limit of voltage instability beginning. Operators at the utilities company are able to determine the status of the system based on the margin which roles as an indicator. The graph after $0.16 \mathrm{sec}$ is no longer valid since the power flow solution after a voltage collapse diverges.

\section{CONCLUSION}

The investigation of a voltage instability phenomenon is based on TNB $132 \mathrm{kV}$ load area. Simulation data from PMUs were collected from TNB-R. The conclusion can be concluded based on the findings of the investigation as following.

During normal loading condition, the margin index always stays positive. However, when any disturbance occurs, the ratio is definitely approaching zero and decreasing in non linear form. Hence, the main perception is to ensure the index always stay positive and suitable early prevention should be implemented when the index is close to zero.

Besides, whenever the system is approaching the point of collapse, any small changes in the power system will cause load voltage to have major drop, which had proven according to the behaviour of voltage collapse. The maximum power transfer and the load voltage were captured at the same point of collapse as the predicted Thevenin impedance crossing the load impedance.

Last but not least, the importance of real-time voltage stability margin which able to provide a proximity to voltage collapse based on the real power transfer margin, reactive power transfer margin and apparent power transfer margin.

Further extension of the current study will concentrate on the different types of method to estimate the Thevenin parameters. Besides, the investigation area can be further expand by using the IEEE 118 and 300 bus systems in order to achieve more influenceable results.

\section{ACKNOWLEDGEMENT}

The research gratefully acknowledge the contributions of TNB Research and TNB Transmission members for their valuable comments, support and technical cooperation during the process of collecting the PMUs data and also the development works. The authors would like to thank the Ministry of Education, Malaysia (KPM), Ministry of Energy, Green Technology and Water (KeTTHA), Research and Innovation Centre, UTHM for financially supporting 
this research under the Fundamental Research Grant Scheme- KeTTHA (FRGS-KeTTHA) grant No. 0905 and MTUN-CoE Vot.No.C025.

\section{REFERENCES}

Abdullah, S.K.B.S. and N.S.B.N. Yusuf, 2008. Tenaga nasional berhad wide area measurement system based applications. Proceedings of the IEEE 2nd International Power and Energy Conference, Dec. 13, IEEE Xplore Press, Johor Bahru, pp: 962-966. DOI: 10.1109/PECON.2008.4762612

Ajjarapu, V. and A.P.S. Meliopoulos, 2008. Preventing voltage collapse with protection systems that incorporate optimal reactive power control. Power Syst. Eng. Res. Center.

Al-Ammari, R.A., 2002. Voltage stability margin identification using local measurements and linear kalman filter. Eng. J. Qatar Univ., 15: 153-164.

Bishop, G. and G. Welch, 2001. An introduction to the kalman filter. Proc of SIGGRAPH, Aug. 12-17, os Angeles, CA., pp: 2759-3175.

Canizares, C.A., 2002. Voltage stability assessment: Concepts, practices and tools. IEEE/PES Power Syst. Stability Subcommittee. Tech. Rep., SP101PSS.

Chakrabarti, S., E. Kyriakides, B. Tianshu, C. Deyu and V. Terzija, 2009. Measurements get together. IEEE Power Energy Mag., 7: 41-49. DOI: 10.1109/MPE.2008.930657

Foo, K.F.K., 2009. Real time voltage stability monitoring by thevenin impedance estimation with local measurement. Master of Applied Science, The University of British Columbia.

Gavrilas, M., O. Ivanov and G. Gavrilas, 2008. REI equivalent design for electric power systems with genetic algorithms. WSEAS Trans. Circ. Syst., 7: 911-921.

Hill, D.J., 1993. Nonlinear dynamic load models with recovery for voltage stability studies. IEEE Trans. Power Syst., 8: 166-176. DOI: 10.1109/59.221270

Hurtgen, M. and J.C. Maun, 2008. Advantages of power system state estimation using phasor measurement units. Proceedings of the 16th Power Systems Computation Conference, Jul. 14-18, Glasgow, Scotland, pp: 1-7.

Kundur, P., 1994. Power System Stability and Control. 1st Edn., Tata McGraw-Hill Education, New York, ISBN-10: 0070635153, pp: 1176.
Kundur, P., J. Paserba, V. Ajjarapu, G. Andersson and A. Bose et al., 2004. Definition and classification of power system stability IEEE/CIGRE joint task force on stability terms and definitions. IEEE Trans. Power Syst., 19: 1387-1401. DOI: 10.1109/TPWRS.2004.825981

Lee, B.H. and K.Y. Lee, 1991. A study on voltage collapse mechanism in electric power systems. IEEE Trans. Power Syst., 6: 966-974. DOI: 10.1109/59.119236

Minhat, A.R., 2008. Evolutionary Programming (EP) based technique for secure point identification with load shedding technique in power transmission. Master thesis, Universiti Teknologi MARA.

Soliman, S.A., H.K. Temraz and S.M. El-Khodary, 2003. Power system voltage stability margin identification using local measurements. Proceedings of the Large Engineering Systems Conference Power Engineering, May 7-9, IEEE Xplore Press, pp: 100104. DOI: 10.1109/LESCPE.2003.1204687

Taylor, C.W., 1993. Modelling of voltage collapse including dynamic phenomena. Cigré.

Taylor, C.W., 1994. Power System Voltage Stability. 1st Edn., McGraw-Hill Ryerson, Limited, New York, ISBN-10: 0070631840, pp: 273.

TNB, 2011. Announcement on the increase in electricity tariff in peninsular malaysia due to the revision of nature gas price. Revision of Base Tariff and Implementation of Feed-In-Tariff (FiT) for Renewable Energy (RE).

Tsai, S.S. and K.H. Wong, 2008. Adaptive undervoltage load shedding relay design using thevenin equivalent estimation. Proceedings of the IEEE Power and Energy Society General Meeting, Jul. 2024, IEEE Xplore Press, Pittsburgh, PA., pp: 1-8. DOI: 10.1109/PES.2008.4596370

Vaiman, M., K. Bell, Y. Chen, B. Chowdhury, I. Dobson and P. Hines et al., 2012. Risk assessment of cascading outages: Methodologies and challenges. IEEE Trans. Power Syst., 27: 631-641. DOI: 10.1109/TPWRS.2011.2177868

Vu, K., M.M. Begovic, D. Novosel and M.M. Saha, 1999. Use of local measurements to estimate voltage stability margin. IEEE Trans. Power Syst., 14: 10291035. DOI: $10.1109 / 59.780916$

Vu, K.T., D.E. Julian, J.O. Gjerde and M.M. Saha, 2001. Applications and methods for Voltage Instability Predictor (VIP). U.S. Patent No. 6,249,719, U.S. Patent and Trademark Office, Washington, DC. 
Warland, L. and A.T. Holen, 2001. A voltage instability predictor using local area measurements (VIP++). IEEE Porto Power Tech Proc. DOI: 10.1109/PTC.2001.964729
Zhang, P., L. Min and J. Chen, 2012. Measurement based on voltage stability monitoring and control. U.S. Patent, U.S. Patent and Trademark Office, Washington, DC. 